I wish to thank Ur. H. L. Penman and A. H. Weir for helpful discussions.

Rothamsted Experimental Station,

$$
\text { W. W. EMERSON }
$$

Harpenden, Herts.

Aug. 28.

1 Wilkins, M. F. H., et al., Nature, 168, 127 (1956).

2 Ross, C. S., and Hendricks, S. B., U.S.D.I. Prof. Paper 205-B (1945).

\section{Noise Radiation from Tropical Thunder- storms in the Standard Broadcast Band}

AN objective method of measuring atmospheric noise interference to broadcasting based on subjective observations and statistical considerations has been reported ${ }^{1}$. Results of systematic measurements by the method in the 3 and $5 \mathrm{Mc} / \mathrm{s}$. bands have been published ${ }^{23}$. It has been shown that these results can be satisfactorily explained on the basis of the available data on lightning discharges ${ }^{4}$, the distribution of thunderstorm days, the growth and decay of thunderstorms ${ }^{6}$, and the laws of propagation. For this purpose, the available data on lightning discharges have been utilized to deduce an idealized statistically valid representation of a typical flash as it occurs in a tropical thunderstorm ${ }^{4}$. It is found that

$$
P=45 / f^{2}
$$

where $P$ is the power in watts and $f$ is the frequency in $\mathrm{Mc} . \mathrm{s}$.

The calculations are with specific reference to the band-width and time-constant characteristics of the noise meter. It has been assumed that there are three strokes to a flash and that all thunderstorms recorded by weather offices as 'thunderstorm days' radiate noise. It has, however, been clearly stated that the equation must break down for frequencies below $1 \mathrm{Mc} . \mathrm{s}$. This statement was based partly on theoretical considerations and partly on the preliminary investigations ${ }^{1}$. It was therefore folt that measurements of atmospheric noise interference to broadcasting at frequencies below I Mc./s. would be valuable not only from the point of view of getting noise data but also for theoretical evaluations. Hence, noise measurements were carried out at 620 and $930 \mathrm{kc} . / \mathrm{s}$. at Poona for $18-23 \mathrm{hr}$. I.S.T., during $1954-56$, by C. G. Khot under my direction. Occasionally, observations have also been taken for 12-24 hi. The results have been analysed and the noise data deduced as usual.

Estimates of noise were made as usual by using the power given by equation (1). These estimates were invariably found to be higher than the measured values. Further, our study of individual thunderstorms simultaneously at a number of frequencies had indicated something abnormal at frequencies below $1 \mathrm{Mc}$ /s. In order, therefore, to attempt a possible explanation of the results, the lightning discharge data and the original theoretical calculations were re-examined. It appears that the discharges within the cloud or into the air do not radiate any significant power at frequencies below $1 \mathrm{Mc}$./s., that is, noise radiation at frequencies below $1 \mathrm{Mc}$./s. appears to arise entirely from thunderstorms in which the discharge strikes the ground. Further, even in these cases, it is only the stepped leader that is responsible for the radiation of noise. There appears to be no radiation from the dart leaders.
Calculations carried out on the basis outlined above resulted in the following expression for the noise power radiated :

$$
P=\frac{16 \cdot 2}{f^{2}} \cdot \frac{1}{1+\frac{\delta^{2}}{4 \pi^{2} f^{2} \cdot 10^{12}}} \text { watts }
$$

$\delta$ is the constant in the expression for the exponential rise of current in the discharge.

Using equation (2) and the laws of propagation, noise values were estimated, and these appear to agree well with measured values. It appears that equation (2) holds up to $500 \mathrm{kc} . / \mathrm{s}$. or even lower. This lower limit has to be evaluated by further experiments. The higher frequency up to which the equation holds lies between 1 and $3 \mathrm{Mc}$./s. and detailed investigations in this region should prove interesting.

This communication is being published in view of its possible interest to those studying the wave-forms of atmospheries and other problems of thunderstorm electricity during the forthcoming Geophysical Year. The complete theoretical and experimental work will be published in due course elsewhere.

\section{S. V. Channrasheghar Arya}

L.D. College of Engineering, Ahmedabad 9. Aug. 22.

1 Aiya, S. V. C., J. Atmos. Terr. Phys., 5, 230 (1954)

Aiya, S. V. C., and Phadke, K. R., J. Atmos. Terr. Phys., 7, 254 (1955).

${ }^{3}$ Phadke, K. R., J. Inst. Telecomm. Eng. (India). 1, 136 (1955)

"Aiya, S. V. C., Proc. Inst. Radio Eng., 43, 966 (1955)

$\checkmark$ Aiya, S. V. C., J. Sci. Indust. Res., 13 A, 314 (1954).

- Aiya, S. V. C., Khot, C. G., Phadke, K. R., and Sane, C. K., J. Sci. Indust. Res., 14 B, 361 (1955).

\section{Temperatures in the Earth's Interior}

THE melting-point gradient for the Earth's mantle has been determined by Uffen ${ }^{1}$ from Lindemann's law ; the results yield an upper limit on the actual temperature. Simon ${ }^{2}$ and Bullard $^{3}$ have made estimates, from Simon's semi-empirical fusion equation, of melting temperatures in the Earth's core, which provide a lower limit to the corresponding temperature in the liquid outer core.

In a recent paper ${ }^{4}$, I have derived the Lindemann law from the theory of Debye and Waller for the thermal dependence of the intensity of reflexion of X-rays by a crystal. The development yields ${ }^{5}$ a direct derivation of the Simon melting equation, which can be written

$$
P_{m}=A\left[\left(T_{m} / T_{m, o}\right)^{B_{-}-1}\right]
$$

where $T_{m}$ and $T_{m, o}$ are the absolute melting temperatures at pressure $P_{m}$ and zero, respectively, and $A$ is a constant. If the Earth's core is presumed to consist of iron, my results show that

$$
B=\left(6 \gamma_{m, o}+1\right) /\left[2\left(3 \gamma_{m}, o-1\right)\right]
$$

where $\gamma_{m}, o$ is the Grüneisen constant of the solid at fusion under zero pressure. The applicability of equation (2) follows ${ }^{8.6}$ from the fact that iron is sufficiently incompressible for osculating approxim: tions at the origin of the fusion curve to be valid. An 